九州大学学術情報リポジトリ

Kyushu University Institutional Repository

\title{
Greening Saline Waste Land With Peoples Participation in Faisalabad, Pakistan
}

Awan, A. R.

Nuclear Institute for Agriculture and Biology

Omura, Hiroshi

Faculty of Agriculture, Kyushu University

Paudel, Prem Prasad

Faculty of Agriculture, Kyushu University

Kubota, Tetsuya

Faculty of Agriculture, Kyushu University

他

https://doi.org/10.5109/9335

出版情報: 九州大学大学院農学研究院紀要. 52 (2)，pp.445-449，2007-10-29. Faculty of Agriculture, Kyushu University

バージョン :

権利関係 : 


\title{
Greening Saline Waste Land With Peoples Participation in Faisalabad, Pakistan
}

\section{A. R. AWAN ${ }^{1}$, Hiroshi OMURA ${ }^{2 *}$, Prem Prasad PAUDEL, T. KUBOTA and Z. ASLAM}

\author{
Laboratory of Forest Conservation, Division of Forest Environment and Management Sciences, \\ Department of Forest and Forest Products Science, Faculty of Agriculture, \\ Kyushu University, Fukuoka 812-8581, Japan \\ (Received June 29, 2007 and accepted July 17, 2007)
}

\begin{abstract}
Limitation to agricultural productivity is imposed by the root zone salinity. The salinity problem was occurred through rise in water table and deposition of salts on the surface through capillary action. In Pakistan, about 6.8 million hectares area is salt affected and is causing annual losses of 3 billion US dollar. For combating salinity, the engineering options like constructing side drainage through tube well, surface drains, subsurface tile drains and on farm water management problem are becoming expensive and energy intensive. As an alternative, establishment of salt tolerant plants through peoples participation are being more advocated to deal with the problem. The people form a group called "Saline Agriculture Farmer Association" and the programs are implemented through the people's participation. A wide range of salt tolerant plant material has been screened for successful introduction. Saline agriculture technology (cultivation of salt tolerant plants on saline lands) is a low input technology, farmer oriented and environment friendly having profound effect on physical, chemical and biological parameters of the soil. Moreover, economic returns from saline environments are conceivable with in a span of few months.
\end{abstract}

\section{INTRODUCTION}

Limitation to agricultural productivity imposed by the root zone salinity and uses of brackish irrigation water are severe around arid areas. The salinity problem occurs through rise in water table and deposition of salts on the surface through capillary action. In Pakistan, about 6.8 million hectares area is salt affected causing annual loss of 3 billion US dollar. The salt is accumulated in cultivated land, forming white effloresce as can be seen in Photo 1. The salt accumulation is not only problem for cultivated land but is causing serious prob-

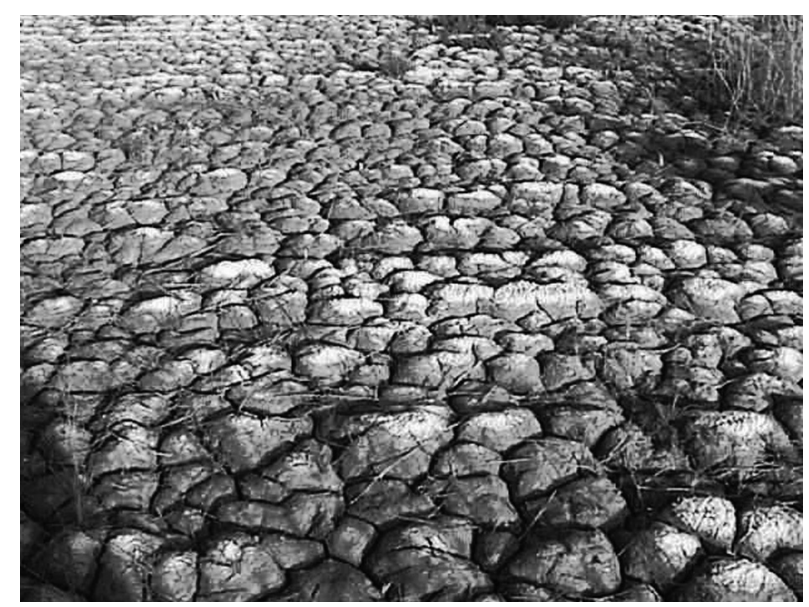

Photo 1. View of white effloresce soil caused due to accumulation of salt.

Nuclear Institute for Agriculture and Biology, P. O. Box 128, Faisalabad, Pakistan

Laboratory of Forest Conservation, Division of Forest Environment and Management Sciences, Department of Bioresources and Bioenvironmental Sciences, Faculty of Agriculture, Kyushu University, Fukuoka, 812-8581, Japan

* Corresponding author (E-mail: homura@agr.kyushu-u.ac.jp) lems to rural houses too. Salt deposition is reducing span of the rural houses as the structures are disintegrated due to high salt contents as shown in Photo 2.

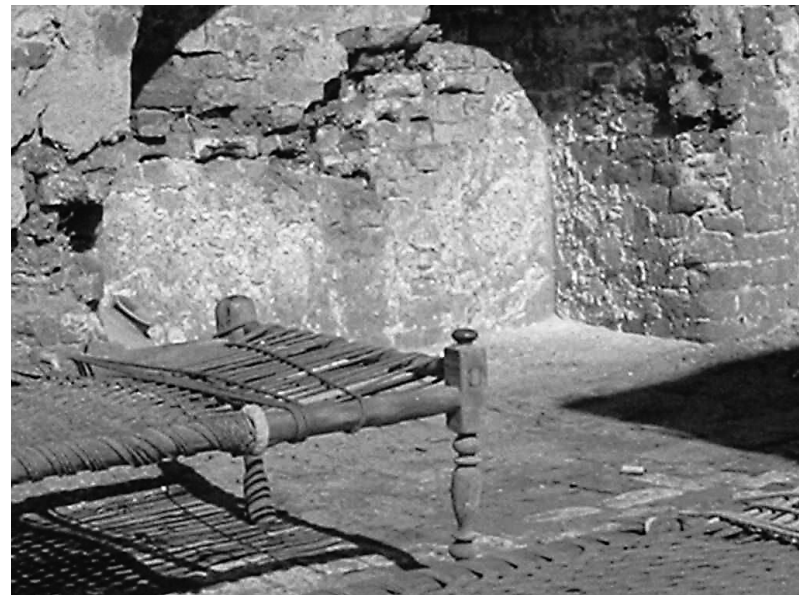

Photo 2. View of disintegrated wall of buildings caused due to salt accumulation.

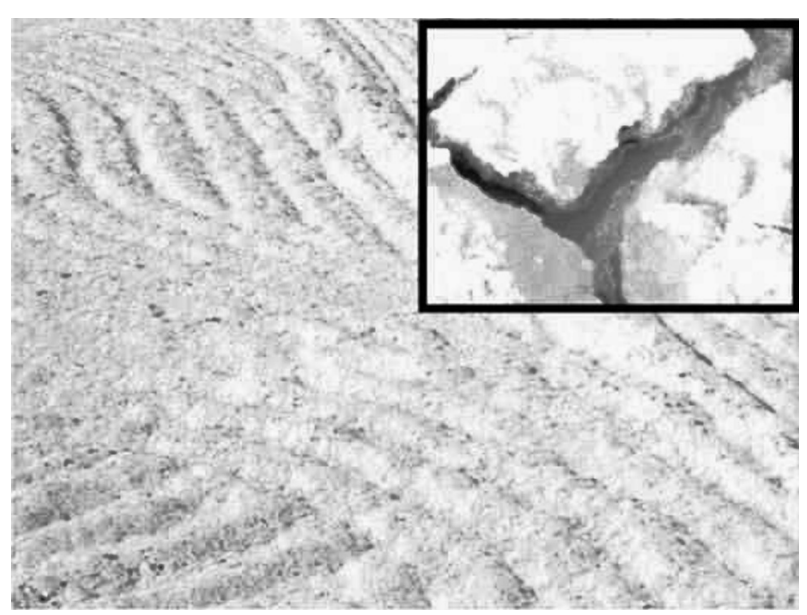

Photo 3. View of salt affected wasteland with low water permeability, with water-logging as seen in picture box. 


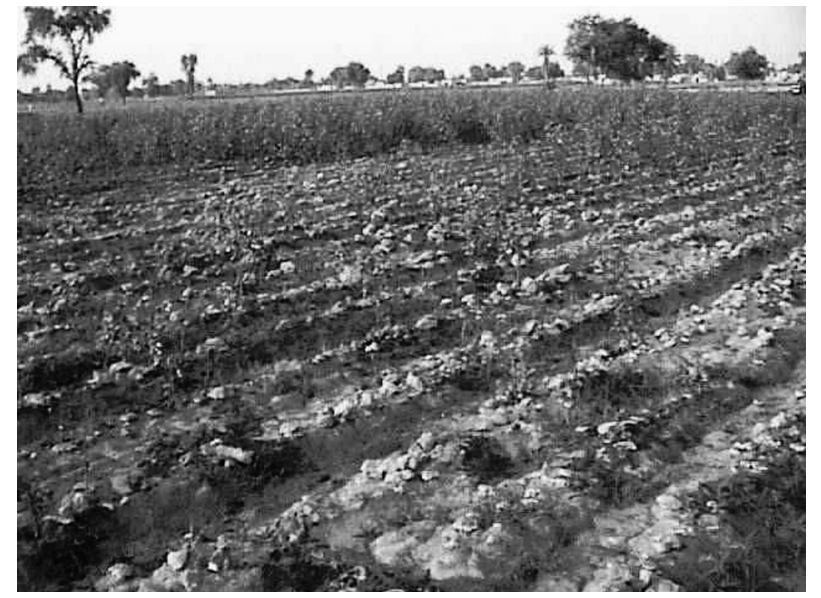

Photo 4. Patchy growth and reduced productivity in marginal saline land causing economic losses to the farmers.

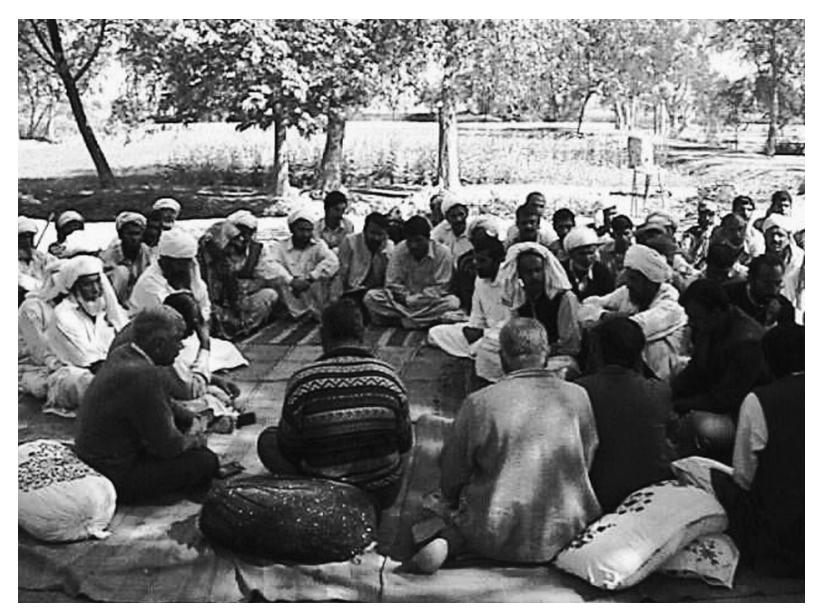

Photo 5. Farmers are being organized in associations to participate in project activities.

Some wasteland parts are affecting through low water permeability and causing water logging as can be seen in Photo 3 and 4. Consequently, the farmers are suffering from low productivity and economic losses. In this situation, the farmers who are constantly affecting by low economic productivity are organized in a group for shearing their common ideas and programs. They organized in a small group and form "Saline Agriculture Farmer Association" for solving the problem of salinity. Sometimes they organize a meeting to discuss their problems, and future plan as shown in Photo 5.

\section{Efforts and progress for reducing salinity}

The salinity problem is currently given wide attention by the Government of Pakistan and is formulating policies to minimize the problems. Among several management options available for combating salinity, the engineering option has been tried on a large scale in Pakistan by leaching and drainage through tube well, surface drains, subsurface tile drains and on farm water management. This option is expensive and energy intensive and does not match current economic resources of the country. Therefore, presently greenery based strategies are being more advocated to address the problem. For the successful establishment of plants, the technical staffs from Government offices, first provides training opportunity to farmers about nursery rising as shown in Photo 6. The people get benefit on how to grow plants in nursery stages and in wasteland field. There is gender equity opportunity and policy so female also get involved to participate in nursery training program. After getting successful training, the farmers themselves are able to establish the suitable salt tolerant species in the nursery scale as shown in Photo 7.

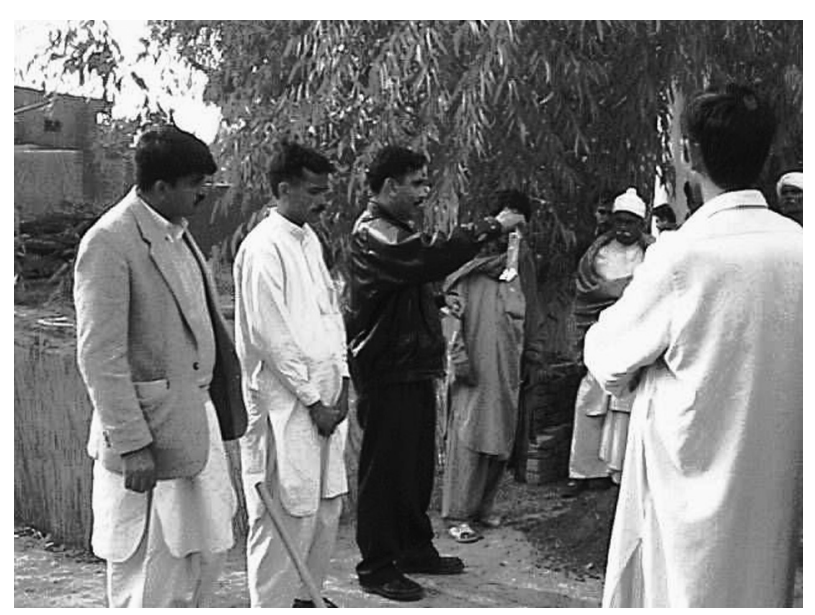

Photo 6. Farmers are being trained for nursery raising by project team as a part of capacity building in farming community.

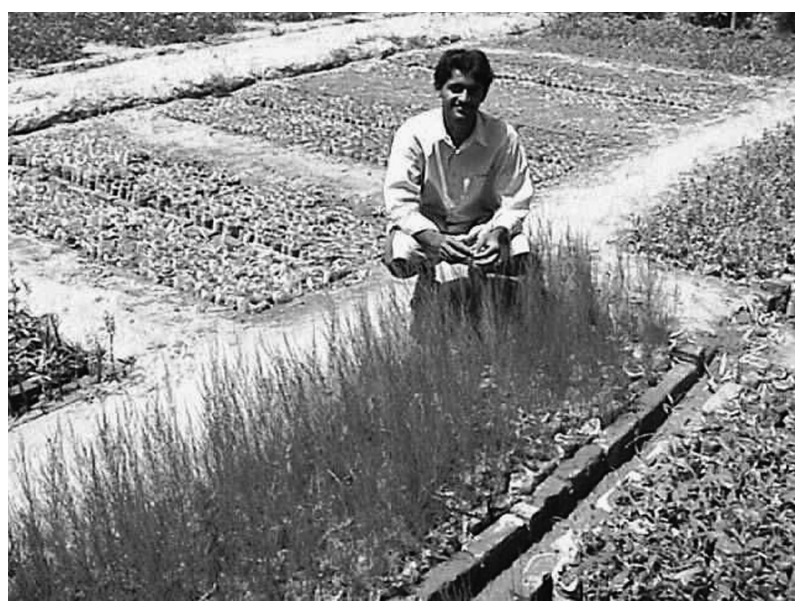

Photo 7. Farmer participatory nursery raised by community as a result of successful training.

Due to the higher clay content and compact soil, it is very difficult to form a holes for plantation. The holes for large scale plantation are usually made using tractor mounted digger and sometimes prepared manually as shown in Photo 8 and 9.

The saline resistant species like Acacia ampliceps, Photo 10 are planted in saline wasteland. The plant species after successful growth, peoples usually used for forage to feed their cattle. This helps to develop small scales animal husbandry, an economical enterprises to rural poor farmers. In addition, the degraded area also 
becomes ecologically significant with increasing aesthetic values as shown in Photo 11.

Large scales plantations of multipurpose salt resistant species can be seen in flat cultivated land, Photo 12. The marginal lands are converting into good productive areas after adopting saline agriculture management

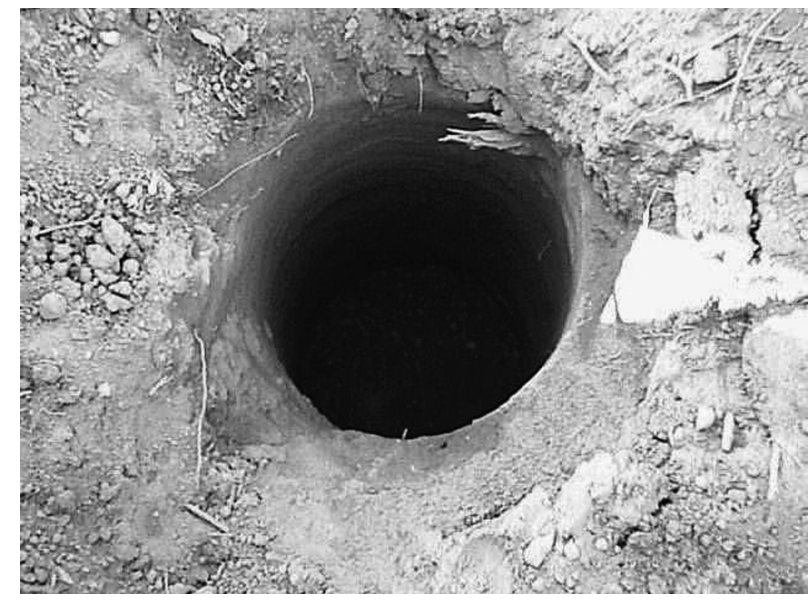

Photo 8. View of a mechanically made hole for plantation.

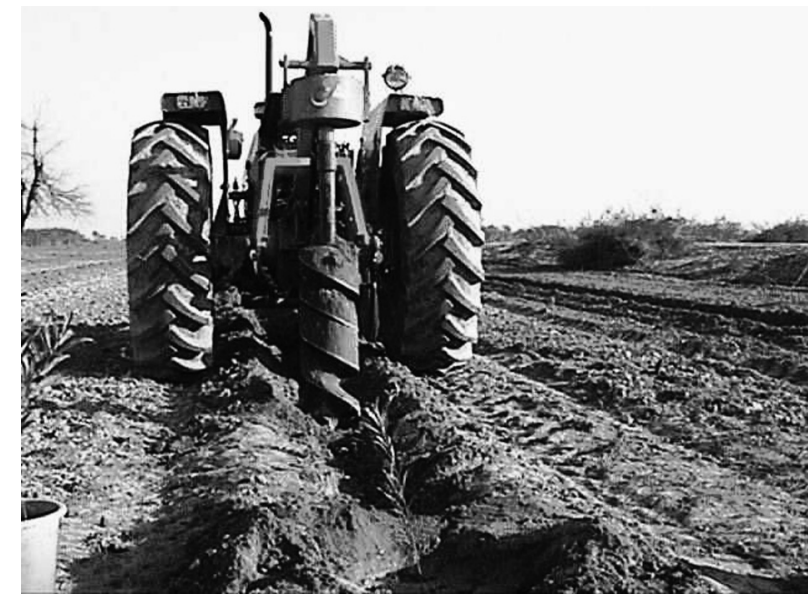

Photo 9. Holes for plantation are being made by tractor mounted post hole digger.

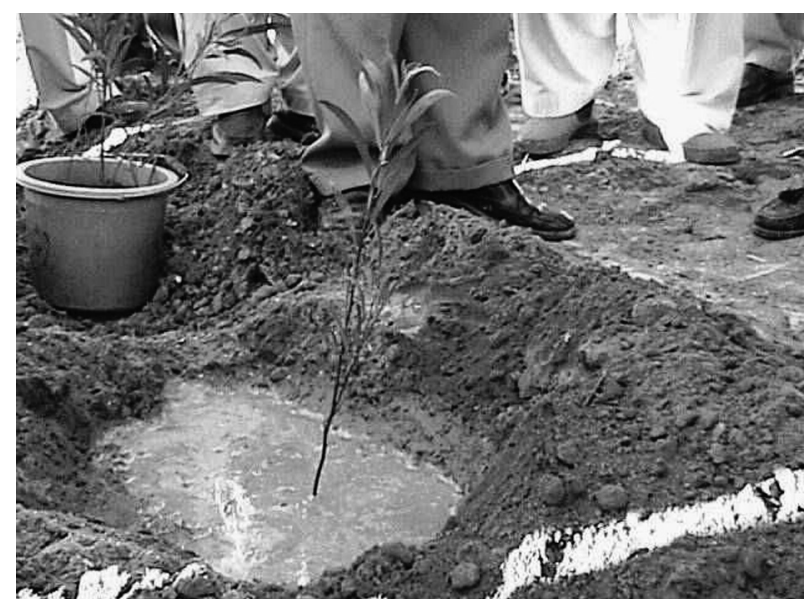

Photo 10. Newly planted sapling of Acacia ampliceps in saline waste land. practices, Photo 13. In overall, the efforts and progress done to rehabilitate the waste, degraded land by using vegetative techniques are successful and are supposed to be replicate for the similar condition areas.

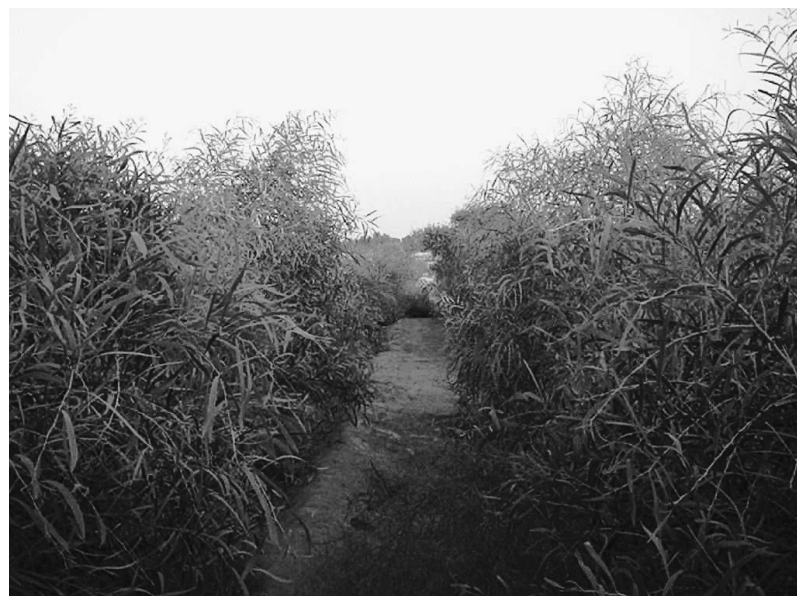

Photo 11. View of established plantation that is increasing economic and aesthetic value of barren waste land.

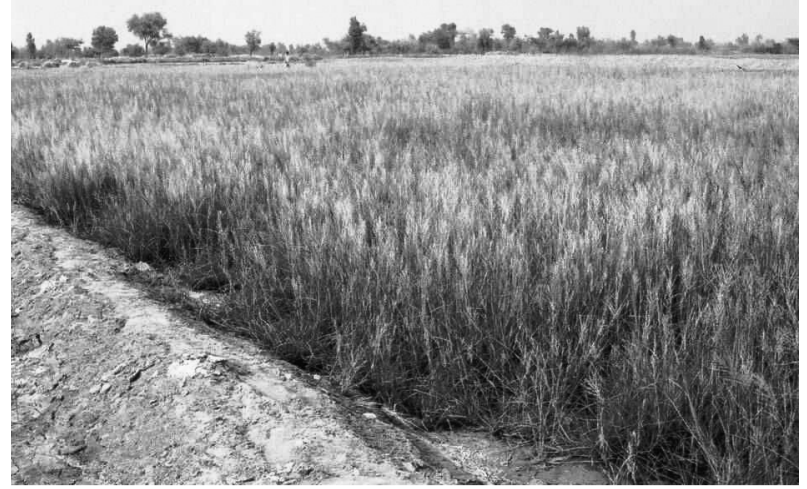

Photo 12. View of lush green growth of Leptochloa fusca in a highly saline wasteland and plant is used for forage by livestock.

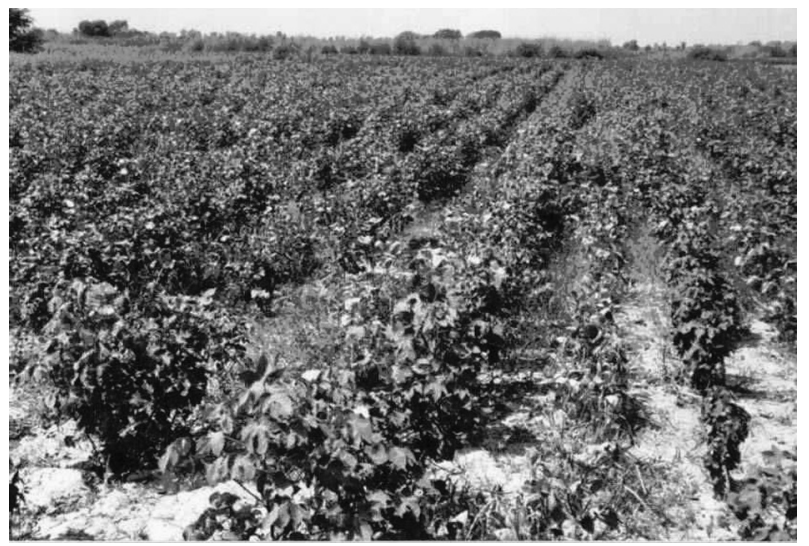

Photo 13. View of a good productive marginal saline land after management. 


\section{Studies on economic utilization of salt affected soils}

Nuclear Institute for Agriculture and Biology (NIAB), Faisalabad, Pakistan has employed nuclear and other advanced techniques in studies on utilization of salt affected soils. About 50 plant species showing high salt tolerance have been found suitable for areas where the underground water is also saline. These include fuel wood plants (Eucalyptus, Acacia sp.), feed plants (kallar grass, Sporobolus grass), and food plants (Barley, Brassica and wheat). The biomass obtained from salt tolerant plants can be used as fuel wood, timber, green or composted manure, forage or for conversion into board and paper. The plants themselves can serve as soil cover to stop erosion. Water requirements of the selected species and their evapo-transpiration potentials had been established.

Growth of Kallar grass (Leptochloa fusca) on salt-affected soil using brackish irrigation water demonstrated improvement in soil physical state on available water, hydraulic permeability, structural stability, bulk density, chemical properties like EC, pH, SAR, organic matter \& soil salinity, and mineralogical properties. Hydrological studies using isotopic techniques explored the subsurface aquifer characteristics, water chemistry and sources of recharge in different areas causing salinity hazard. Satisfactory growth of the plantations justified the option of tree growing as a control measure for shallow water tables and salinization with proper management.

\section{Saline agriculture farmer participatory develop- ment project}

This project aims at rehabilitation of farming communities and their salt affected lands in saline environments with their active involvement in decision-making and by sharing relevant technologies with them. Its main objectives include to;

1. disseminate and optimize saline agriculture technology with the active participation of farmers through community based organizations,

2. maximize the economic returns from salt affected soils by diversification and value addition to farm products,

3. training and capacity building in the farming community ensuring gender equity.

The project objectives are being realized through organizing the farming communities in Saline Agriculture Farmers Associations (SAFAs) who periodically conduct business meetings to catalyze the development work and provide feed back to project staff. The project staff has conducted several practical courses for imparting training to the farmers on nursery raising, planting techniques on salt-affected soils, use of amendments like gypsum and mineral acids, advanced production technology of major crops, animal health care, vaccination against diseases and preparation of feed blocks. Saline aquaculture with main emphasis on utilization of on-farm salt tolerant vegetation in place of artificial feed is also gaining momentum to get higher production of fish.

\section{DISCUSSION}

Since salinity in soil and ground water restrict plant growth and development, therefore, a wide range of salt tolerant plant material has been screened for successful management. Salt tolerance studies were conducted on trees, shrubs and grasses species. From field condition, it was revealed that all kinds (either tree species or grasses) have shown ability to sustain economical growth at higher salinity regimes. Saline agriculture technology (cultivation of salt tolerant plants on saline lands) was a low input technology, accepting by farmers. It was recognized as environmentally friendly having profound effect on physical, chemical and biological parameters of the soil. Moreover, economic returns from saline environments are conceivable with in a span of few months. Nuclear Institute for Agriculture and Biology (NIAB), Faisalabad, Pakistan is actively engaging in developing pioneer technology. The technology has been demonstrated on research stations of NIAB on large scale. A number of salt tolerant plants were successfully grown, and the outlook of a barren and waste landscape was changed to green crop cover in a few years time. In 1996, International Atomic Energy Agency (Vienna) initiated an Inter-regional Model Project on 'Economic utilization of saline wastelands and brackish water for crop production'. Nine countries of Africa and Asia having similar salinity problem, viz., Pakistan, Jordan, Iran, Egypt, Tunisia, Morocco, Syria, United Arab Emirates and Algeria, are taking part in this project. The results obtained from the pilot areas might be useful to replicate in the same environmental sites.

\section{FUTURE VISION}

In order to optimize and sharpen saline agriculture technology, soil scientists emphasize in cooperation with agronomists and plant breeders to design site specific plant based strategies to overcome multiple soil constraints, with vertical and lateral variations and to develop plant based solutions for salinity. The examination on the ability of plants to adopt and ameliorate various growth constraints, soil modification by management of agro forestry ecosystems and use of biological approach for economical utilization of salt affected soils should be emphasized. Thus it will not only help to reverse environmental degradation but would also enhance aesthetic value of waste lands. Advance training of farmers, project staff in saline agriculture technologies at regional, national and international levels is also emphasized as human resources so developed would be instrumental in planning and running similar projects in other countries having similar problem.

\section{CONCLUSION}

Greening a saline and wasteland part is not an easy task. Not only irrigated land that is becoming saline, but also ground water is becoming saline. The hardware and other engineering structures are expensive and might 
not be viable, and priority to use plants for site restoration is much more cost effective solution. Different plant species have tested and grown successfully which were suitable for saline site treatment. The adopted techniques might be possible to replicate in other similar environmental sites. It is encouraged for the growth and propagation of indigenous plants. Local people were aware about the saline problem. Their traditional skills, knowledge and participation on saline problems were useful. The management of the saline waste using greenery method was socially acceptable, economically viable and ecologically friendly. 